\title{
Clinical Profile of Muco-Cutaneous Lesions in Dengue Fever in Children at a Tertiary Care Hospital
}

\author{
Mohd Irfan Inamdar ${ }^{1}$, Varsha Suresh Ahirrao ${ }^{2}$ \\ ${ }^{1}$ Senior Resident, Department of Pediatrics, GIMS, Gulberga, Karnataka, ${ }^{2}$ Associate Professor, Department of Pediatrics, MVJMC and RH, Hoskote, Karnataka.
}

\section{Abstract}

Background: Dengue is arthropod borne viruses, they use mosquitoes as vector. AedesAlbopictus although could be a suitable vector, the Aedesaegypti work as the most efficient carrier, vectors also serve to amplify viral replication.The frequency of Dengue and its complications has increased over the past few years, especially in rural area. Dengue has a wide spectrum of clinical presentation, unpredictable clinical evolution and outcome, especially in children. Subjects and Methods: The study was conducted over a period of two years on Dengue cases in Paediatrics department of Medical College and Research Hospital.Children with fever of acute onset, with clinical featuressuggestive of Dengue fever as described in WHO 2012 Guidelines.Children with age less than 18 years, admitted as Dengue feverbased on clinical features as described in WHO 2012 Guidelines and positive Ns1 Ag and/or Dengue IgM. Results: Dengue fever had fewer mucosal manifestations compared to cutaneous manifestations. 144 cases had mucosal manifestations. Scleral Congestion/Conjunctival Haemorrhage was the most common manifestation seen in 69 cases $(47.92 \%)$, followed by Erythema and Crusting of Lips and Tongue (31.94\%), vesicles on soft palate or throat congestion (29.86\%) and Palatal Haemorrhage and Gingival bleeding (11.80\%). Conclusion: Flushing is the most common cutaneous manifestation in our study followed by macular rash, petechiae and pruritus. Flushing is an early feature occurring around day 2 of illness, whereas, pruritus is a late manifestation, occurring around day 5 of illness. Thus, Dengue should be strongly considered in any child presenting with fever and flushing.

Keywords: Muco-cutaneous lesions, Dengue fever, Children.

Corresponding Author: Dr. Varsha Suresh Ahirrao, Associate Professor, Department of Pediatrics, MVJMC and RH, Hoskote, Karnataka.

Received: September 2019

Accepted: September 2019

\section{Introduction}

Dengue disease is an acute infectious disease caused by four serotypes of dengue virus, and is the most prevalent mosquito-borne viral disease in humans, occurring in tropical and subtropical countries of the world where over 2.5 billion people are at risk of infection. The World Health Organization has estimated 50 million cases of dengue fever and several hundred thousand cases of dengue haemorrhagic fever occur each year, depending on the epidemic activity.Some 1.8 billion of the population at risk for dengue worldwide live in member states of the WHO South-East Asia Region and Western Pacific Region, which bear nearly $75 \%$ of the current global disease burden due to dengue. ${ }^{[1]}$

Four related yet antigenically distinct viruses belonging to Flaviviridae family cause dengue illnesses. Infection with one dengue serotype provides lifelong immunity to that particular virus, but other serotypes have no cross protective immunity. Humans and mosquitoes are the principal hosts of dengue virus. Dengue is arthropod borne viruses, they use mosquitoes as vector. AedesAlbopictus although could be a suitable vector, the Aedesaegypti work as the most efficient carrier, vectors also serve to amplify viral replication. ${ }^{[2,3]}$
The frequency of Dengue and its complications has increased over the past few years, especially in rural area. Dengue has a wide spectrum of clinical presentation, unpredictable clinical evolution and outcome, especially in children. Early prediction of Dengue infection during any febrile illness, using clinical and laboratory markers, is essential for initiating early appropriate management. ${ }^{[4]}$ Mucocutaneous manifestations may be the presenting feature of dengue fever. It needs to be differentiated from other infectious and non-infectious causes of fever with rash. Hence, a clear understanding of mucocutaneous manifestations may help in the clinical diagnosis of dengue fever and institution of early appropriate management. Until now only a very few studies are available regarding the spectrum of mucocutaneous features of dengue fever in children.

\section{Subjects and Methods}

\section{Study Design}

Hospital based Prospective Observational study. 
The study was conducted over a period of two years on Dengue cases in Paediatrics department of Medical College and Research Hospital.

\section{Study Population}

Children with fever of acute onset, with clinical featuressuggestive of Dengue fever as described in WHO 2012 Guidelines

\section{Inclusion Criteria}

Children with age less than 18 years, admitted as Dengue feverbased on clinical features as described in WHO 2012 Guidelines and positive Ns1 Ag and/or Dengue IgM.

\section{Exclusion Criteria}

A. Children who cannot be followed up till 7 days.

B. Mucocutaneous changes due to drugs or blood transfusion.

C. Children with pre-existing diseases on Chronic medications.

D. Children with pre-existing skin diseases.

E. Children with dengue fever associated with other illnesses. example: chikungunya, malaria, typhoid, etc.

\section{Results}

Out of 372 clinically suspected dengue patients, 296 cases were confirmed as dengue fever by dengue antigen and serology test. Those 296 patients were included in the study.

Table 1: Categorization According To Serology ( $\mathrm{N}=372)$

\begin{tabular}{|l|l|l|}
\hline Serology Group & No of Cases & Percentage \\
\hline Dengue $(+)$ & 296 & 79.57 \\
\hline Dengue $(-)$ & 76 & 20.43 \\
\hline Total & 372 & 100 \\
\hline
\end{tabular}

Table 2: Dengue Fever With and Without Mucocutaneous Manifestations ( $\mathrm{N}=\mathbf{2 9 6}$ )

\begin{tabular}{|l|l|l|}
\hline & No of cases & Percentage \\
\hline $\begin{array}{l}\text { Dengue fever with mucocutaneous } \\
\text { manifestations }\end{array}$ & 211 & 71.28 \\
\hline $\begin{array}{l}\text { Dengue fever without mucocutaneous } \\
\text { manifestations }\end{array}$ & 85 & 28.72 \\
\hline Total & 296 & 100 \\
\hline
\end{tabular}

Out of 296 dengue cases, 211 cases had obvious mucocutaneous manifestations, (i.e.71.28\%).

\begin{tabular}{|l|l|l|}
\hline Table 3: Different Cutaneous Manifestations of Dengue \\
\hline Cutaneous Manifestations & No of Cases & Percentage \\
\hline Macular Rash & 96 & 45.50 \\
\hline Papular Rash & 32 & 15.17 \\
\hline Pruritus & 90 & 42.65 \\
\hline Morbilliform Rash & 30 & 14.22 \\
\hline Ecchymosis & 12 & 5.69 \\
\hline Desquamation & 15 & 7.11 \\
\hline Petechia & 87 & 41.23 \\
\hline Flushing & 198 & 93.84 \\
\hline
\end{tabular}

560 cutaneous manifestations were seen in 203 cases. Many patients had more than one cutaneous manifestations. Predominant Cutaneous manifestations of dengue fever were flushing, macular rash and petechie. Flushing was the most common manifestation seen in 198 cases (93.84\%), followed by Macular rash seen in 96 cases (45.50\%) ,Pruritus in 90 cases(42.65\%), and Petechia in 87 cases (41.23\%).

Table 4: Different Types of Mucosal Manifestations

\begin{tabular}{|l|l|l|}
\hline Mucosal Manifestations & $\begin{array}{l}\text { No of } \\
\text { Cases }\end{array}$ & Percentage \\
\hline Oral (Vesicles on Soft Palate) Throat Congestion & 43 & 29.86 \\
\hline Erythema and Crusting of Lips and Tongue & 46 & 31.94 \\
\hline Scleral Congestions/ Conjuctival Haemorrhage & 69 & 47.92 \\
\hline Nasal/Palatal Haem orrhage/gingival bleeding & 17 & 11.80 \\
\hline
\end{tabular}

Dengue fever had fewer mucosal manifestations compared to cutaneous manifestations. 144 cases had mucosal manifestations.Scleral Congestion/ Conjunctival Haemorrhage was the most common manifestation seen in 69 cases $(47.92 \%)$,followed by Erythema and Crusting of Lips and Tongue (31.94\%), vesicles on soft palate or throat congestion (29.86\%) and Palatal Haemorrhage and Gingival bleeding $(11.80 \%)$.

Table 5: Cutaneous Manifestation with Day of Occurrence

\begin{tabular}{|l|c|c|l|}
\hline $\begin{array}{l}\text { Cutaneous } \\
\text { Manifestations }\end{array}$ & $\begin{array}{l}\text { Occurr } \\
\text { ence in } \\
\text { Days }\end{array}$ & $\begin{array}{c}\text { Mode } \\
\text { in } \\
\text { Days }\end{array}$ & $\begin{array}{l}\text { Average No of Days } \\
\text { (Mean } \pm \text { SD) }\end{array}$ \\
\hline Macular rash & $2-4$ & 3 & $2.98 \pm 0.57$ \\
\hline Papular rash & $2-4$ & 3 & $3.16 \pm 0.51$ \\
\hline Morbilliform rash & $3-5$ & 4 & $4.44 \pm 0.64$ \\
\hline Pruritis & $5-7$ & 5 & $5.54 \pm 0.57$ \\
\hline Ecchymosis & $4-6$ & 4 & $4.33 \pm 0.65$ \\
\hline Desquamation & $4-6$ & 5 & $5.14 \pm 0.64$ \\
\hline Petechia & $3-6$ & 4 & $3.87 \pm 1.17$ \\
\hline Flushing & $2-4$ & 2 & $2.45 \pm 0.50$ \\
\hline
\end{tabular}

Table 6: Mucosal Manifestations with Day of Occurrence

\begin{tabular}{|l|l|l|l|}
\hline Mucosal Manifestation & $\begin{array}{l}\text { Occurrence } \\
\text { in Days }\end{array}$ & $\begin{array}{l}\text { Mode in } \\
\text { Days }\end{array}$ & $\begin{array}{l}\text { Average No } \\
\text { Days (Mean } \\
\pm \text { SD) }\end{array}$ \\
\hline $\begin{array}{l}\text { Vesicles on Soft } \\
\text { Palate/Throat congestion }\end{array}$ & $3-4$ & 3 & $3.48 \pm 0.50$ \\
\hline $\begin{array}{l}\text { Erythema and Crusting of } \\
\text { Lips and Tongue }\end{array}$ & $3-4$ & 4 & $3.66 \pm 0.48$ \\
\hline $\begin{array}{l}\text { Scleral } \\
\text { Congestion/Conjunctival } \\
\text { Haemorrhage }\end{array}$ & $2-5$ & 3 & $3.42 \pm 0.60$ \\
\hline $\begin{array}{l}\text { Nasal or Palatal } \\
\text { Haemorrhage / Gingival } \\
\text { Bleeding }\end{array}$ & $4-5$ & 4 & $4.28 \pm 0.49$ \\
\hline
\end{tabular}

All the Cutaneous Manifestations of Dengue Fever were further analysed statistically for the day of occurance -range , mode in days and average no of days of occurance with mean and standard deviation. Flushing was early 
manifestations commonly occuring on day 2 of illness, whereas pruritus and desquamation were late manifestations occuring commonly on or after day 5 of illness.

\section{Discussion}

In the present study, various cutaneous manifestations were observed in children with Dengue Fever. Those were compared with various other studies as follows. All variables expressed in percentage.

In the present study, the most common cutaneous manifestation in dengue patients is flushing, seen in 198 cases $(93.84 \%)$ followed by macular rash in 96 cases $(45.50 \%)$, pruritus in 90 cases $(42.65 \%)$, petechia in 87 cases (41.23\%), papular rash in 32 cases (15.17\%),morbilliform rash in 30 cases (14.22\%), desquamation in 15 cases (7.11), last was ecchymosis in 12 cases $(5.69 \%)$.

Flushing is the most common manifestation seen in $93.84 \%$ of the dengue cases similar to study done by Mahboob A et al. ${ }^{[5]}$ where he found it in $77.08 \%$ of dengue cases. Nadiya A et al. ${ }^{[6]}$ found flushing in $28.7 \%$ of dengue patients. Flushing was early feature, transient in nature which usually started between day 2 to day 4 , commonly occurring on day 2 of illness, and mostly involving face.

Study done by Nadia A et al from Lahore, stated that dengue rash was a generalized, macular eruption in $31.7 \%$ while a papular rash was seen in $11.2 \% .{ }^{[7]} \mathrm{In}$ a study by Saleem K et al done in Karachi, a macular rash was reported in $65 \%$ of cases ${ }^{[8]}$ In the present study, macular rash is seen in $45.50 \%$ of cases and Papular rash is seen in $15.17 \%$ of cases. This variation of incidence maybe due to different strains of the virus. ${ }^{[9]}$ In present study, Macular and Papular rash both commonly occurred around day 3 of onset of illness, with a range between 2-4 days.

In present study, generalized morbilli form rash was present in $14.22 \%$. In studies from Pakistan and India generalized morbilli form rash was observed in $65 \%, 81.73 \%$, and $48.3 \%$ respectively, whereas in a study from France ${ }^{10}$ morbilliform rash was observed in $33 \%$ cases. Morbilliform rash occurred between day 3 to day 5 from the onset of fever with most common day being day 4 of illness. Haemorrhagic manifestations are considered to be a hallmark of Dengue Fever, especially of Severe Dengue. In present study, petechiae were present in $41.23 \%$ of the casesother study from Lahore by Nadia Ali et al. reported that petechia in $20 \%$ cases and Saleem and $\mathrm{Shaikh}^{8}$ from Karachi in 35\% cases in their study. In studies from Pakistan and India ecchymotic spots were observed in 4\%, $13.8 \%$ and in $35 \%$ of dengue patients respectively. In the present study, ecchymosis was seen in $5.69 \%$ of the cases. These haemorrhagic cutaneous manifestations including petechiae, purpura and ecchymosis occur mainly on day 3 or day 4 of illness.

Desquamation was observed as a late feature in patients of dengue fever. In present study, it was found in $7.11 \%$ patients. Another study by Nadia aliet al. ${ }^{[6]}$ found desquamation in $12.3 \%$ of dengue patients. Desquamation was mostly seen in late stages of dengue fever. It appeared commonly on day 5 with range being day 4 to day 6 .

Pruritus is also quite common in dengue cases. We found Pruritus in $42.65 \%$ of patients and is generally observed as late feature, occurring commonly around day 5 of illness. Pruritus is reported in different studies, ranging from $16 \%$ to $27.6 \%$. This observation was consistent with reports from Karachi by Saleem k et al. Who found Pruritus in 43.0\% ${ }^{[8]}$ and in Brazil by Noqueiroet al. who found Pruritus in 50.5\% patients $^{[11]}$

Mucosal involvement is estimated to occur in $15 \%$ to $30 \%$ of patients with dengue viral infections which is less compared to cutaneous manifestations. In the present study mucosal manifestation were noted in $48 \%$ of the cases. In another study from Lahore by Mahboob A et al., mucous membrane involvement was quite common and was seen in $85.38 \% .{ }^{[5]}$ Another study from France stated the mucosal involvement of $46.15 \%$ in theirstudy. ${ }^{[10]}$ The mucosal manifestations noted in Dengue viral infections in present study, are conjunctival and scleral injection, small vesicles on the soft palate/throat congestion, erythema and crusting of lips and tongue and palatal haemorrhage and gingival bleeding. According to study by Nadiya A, the most frequent mucosal involvement was oral mucosal involvement i.e. $43.58 \%{ }^{[6]}$ In this present study, oral mucosal involvement in theform of Vesicles on soft palate, erythema of buccal mucosal and throat congestion was found to be $30.06 \%$. Study from Lahore by Mehboob A et al. ${ }^{[5]}$ found oral mucosal involvement to be $66.67 \%$. Oral mucosal involvement usually appears between day 3 to day 4 from the onset of illness. The most common finding of oral mucosa was erythema of buccal mucosa. In present study, erythema and crusting of lips and involvement of tongue was found to be $32.02 \%$. Mahboob A from Lahore in his study, found involvement of lips to be $4.8 \%$, palate to be $2.4 \%$ and tongue to be $1.6 \%$ cumulative to be $10.41 \%$. ${ }^{5}$ Saleem $\mathrm{K}$ et al in his study found $30.0 \%$ involvement of the lips and tongue. ${ }^{[8]}$ These manifestations usually start by day 3 and day 4 from the onset of illness.

Gingivae were hyperaemic and bleeding from gums was seen in $11.80 \%$ patients from the study by MahboobA ${ }^{[5]}$, while in other study from Pakistan, 7\% of patients had bleeding from gums. In one study from Pakistan, haemorrhagic manifestations of Dengue fever in gums were seen in $40 \%$ of patients, while in a study from Japan gum bleeding was more common in adults. In the present study, Nasal bleeding, palatal haemorrhage and gingival bleeding was seen in $3.32 \%$. Nasal bleeding, Gingival bleeding and palatal haemorrhage are seen in cases with Severe Dengue. They usually occur during critical phase. They usually appear on day 4 to day 5 from the onset of illness. 
Other mucosal manifestations included nasal membrane congestion and epistaxis, which was seen in $23.5 \%$. Similarly, $26 \%$ of patients from Liaquat National Hospital had nasal bleeding. In another study from Japan ${ }^{[71]}$ nasal bleeding was most common in children with Dengue.

\section{Conclusion}

Mucosal manifestations are seen in $48 \%$ of children with Dengue fever with scleral congestion and conjunctivalhaemorrhage being the most common mucosal manifestation.

\section{References}

1. Mackenzie JS, Gubler DJ, Petersen LR. Emerging flaviviruses: the spread and resurgence of Japanese encephalitis, West Nile and dengue viruses. Nat Med 2004; 10 (12 Suppl): S98-S109.

2. Edelman R. Dengue vaccines approach the finish line. Clinical infectious diseases: an official publication of the Infectious. Dis Soc Am 2007; 45(Suppl 1): S56-S60.

3. Kurane I, Takasaki T, Yamada K. Trends in flavivirus infections in Japan. Emerg Infect Dis 2000; 6:569-71.

4. Ramos MM, Tomashek KM, Arguello DF, et al. Early clinical features of dengue infection in Puerto Rico. Trans R Soc Trop Med
Hyg 2009;103(9):878-884.

5. Mahboob A, Iqbal Z, Javed R, Taj A, Munir A, Akhtar M. Saleemi, Yaqub F. Dermatological manifestations of dengue fever. J Ayub Med Coll Abbottabad 2012;24(1).

6. Nadiya AA, Malik LM, Jamil A, et al. Cutaneous manifestations in patients of dengue fever. Journal of Pakistan Association of Dermatologists 2012;22(4):320-24.

7. Mahmood K, Jameel T, Aslam HF, et al. Incidence of dengue haemorrhagic fever in local population of Lahore, Pakistan. Biomedica 2009; 25:93-6.

8. Saleem K, Shaikh I. Skin Lesions in Hospitalized Cases of Dengue Fever. J Coll Physicians Surg Pak. 2008;18(10):608-11

9. Sabin AB. In: Viral and Rickettsial infections of man. Rivers TM, Horsfall FL, editors. Philadelphia: JB Lippincott; 1959.

10. Desruelles F, Lamaury I, Rondier M, et al. Cutaneous manifestations of Dengue. Ann DermatolVenerol 1997;124(3):237-41.

11. Noqueiro RM, Miaqostovich MP, Schatzmaya HG et al. Dengue type 2 outbreak in the south of the State of Bahia, Brazil: laboratorial and epidemiological studies. Rev Inst Med Top S Paulo 1995; 37:507-10

12. Hanafusa S, Chanyasanha C, Sujirarat D, et al. Clinical features and differences between child and adult dengue infections in Rayong province, southeast Thailand. Southeast Asian J Trop Med Public Health 2008;39(2):252-9.

Copyright: () the author(s), 2019. It is an open-access article distributed under the terms of the Creative Commons Attribution License (CC BY 4.0), which permits authors to retain ownership of the copyright for their content, and allow anyone to download, reuse, reprint, modify, distribute and/or copy the content as long as the original authors and source are cited.

How to cite this article: Inamdar MI, Ahirrao VS. Clinical Profile of Muco-Cutaneous Lesions in Dengue Fever in Children at a Tertiary Care Hospital. Asian J. Clin. Pediatr. Neonatol.2019;7(3):41-44.

DOI: dx.doi.org/10.21276/ajcpn.2019.7.11

Source of Support: Nil, Conflict of Interest: None declared. 